\title{
E1 Dietari de Jaume Ramon Vila, una obra fragmentada
}

\author{
The Diary of Jaume Ramon Vila, a fragmented work
}

\author{
Arantxa Llàcer Martorell \\ arantxallacer@gmail.com
}

Universitat de València

\begin{abstract}
Resumen: L'estudi d'una obra a partir d'un trasllat comporta un risc, que es veu incrementat en trobar-nos davant una còpia alterada per la mà del copista. En el cas del Dietari de Jaume Ramon Vila, que es conserva a través d'una còpia parcial duta a terme a partir d'una còpia anterior, és imprescindible una tasca d'anàlisi de l'estructura, per tal de tractar d'esclarir en quina mesura ens ha arribat l'obra així com va ser pensada pel seu autor, i quines modificacions ha sofert el text en general i els seus continguts en particular. En aquest article aportem, per tant, el primer estudi que acosta els investigadors a conèixer el Dietari autògraf de mossèn Vila a través d'una intensa tasca de reorganització i recuperació de noticies
\end{abstract}

Palabras clave: dietarística, Jaume Ramon Vila, memòria personal, còpies

Abstract: The study of a work from a copy carries a risk that is increased if we work with a altered copy by the copyist. In the case of Jaume Ramon Vila' Diary, preserved from a partial copy, carried out from a previous copy, we must analyzing the structure, in order to try to clarify how far we have received the work as it was intended by its author, and what changes it has undergone in the text and content. In this article we provide the first study that approaches the researchers know the Diary of Jaume Ramon Vila through an intense activity of reorganization and recovery of news.

Keywords: diaries, Jaume Ramon Vila, first person writtings, copies 


\section{Introducció}

L'autoria del Dietari que estudiem correspon a Jaume Ramon Vila (1569-1638), un intel lectual barceloní, membre de l'estament religiós, i un dels personatges erudits més rellevants de la ciutat comtal d'entre finals dels segle XVI i principis del segle xvII. ${ }^{1}$ Provinent d'una família noble, Vila tenia una vida acomodada, era conegut com el bisbe del Raval (Aymar 1999:700) i passava llargues temporades al Monestir de Sant Jeroni de la Murtra de Badalona. Entre aquestes dues localitzacions va confegir la seua biblioteca, una de les més importants del moment, que ben segurament va ser un espai de reunió dels autors de renom de la Catalunya del XvII, com ara Esteve G. de Bruniquer, Rafael Cervera, Esteve de Corbera, Francesc de Moncada o Dídac de Rocabertí, a més de Dídac de Montfar i Jeroni Pujades, tots ells membres del denominat «cercle erudit» de la Barcelona d'entre 1620 i 1630.

Jaume Ramon Vila va dedicar la seua vida a dues passions, principalment, com eren la fe a Déu i la pàtria catalana, $\mathrm{i}$ aquestes dues facetes vitals es van veure reflectides en la seua producció, que comprén des de textos religiosos, passant per trasllats d'obres de caire històric, la compilació de pamflets, fins arribar a l'escriptura del Tractat d'armoria, un tractat heràldic de gran valor. ${ }^{2}$ Però a més d'aquesta llarga nòmina de còpies i obres originals, Vila també va reservar un espai a l'escriptura personal i va dur a terme la redacció d'un Dietari (AHCB, ms. B-100) que ens ha pervingut, almenys parcialment, i que analitzarem a continuació.

A més, cal destacar, més enllà de la producció més coneguda de l'autor, la possible existència d'un segon dietari a mans de Vila, que no ha arribat fins els nostres dies. El manuscrit A-1, conservat a l'AHCB, conté Copias de varios diarios que guarda el Ayuntamiento de Barcelona de sucesos memorables acaecidos en dicha Ciudad en diferentes tiempos, desde el año 1249 basta 1611. Son de letra de fines del siglo XVI, unos, y otros de principios del XVII i que inclou al quadern tercer uns «Ajustament de coses que no són assí y estan ab un llibre del dietari de Ramon Vila» (Batlle 1999:121); aquest volum va estar en possessió d'Antoni de Capmany, i el va llegar a l'Ajuntament de Barcelona, d'on provenia, a la seua mort. ${ }^{3}$ Alhora, aquest manuscrit ens remet a un altre, el ms. 505 de la Biblioteca de Catalunya, en la descripció del qual-MCEM, núm. 82- s'apunta l'existència «d'un dietari perdut de Jaume Ramon Vila, que no s'ha de confondre amb el conservat al ms. B-100 de l'AHCB, que es limita als anys 1596-1601». Per tant, no descartem la possibilitat que Jaume Ramon Vila fora autor de més d'un dietari o d'una altra obra de tipus memorialístic.

1 Aportem una biografia exhaustiva sobre Jaume Ramon Vila a Llàcer (2016a). També se n’han ocupat, encara que parcialment, Batlle (1999), Aymar (1999) i Roca (1918) i (1928).

2 Descrivim més detalladament el gruix de l’obra de Vila a Llàcer (2015). En aquesta descripció bibliogràfica, però, manca la referència a un volum miscel lani de relacions impreses i manuscrites compilades per Vila i que ja va donar a conèixer Duran (1982).

3 A MCEM (núm. 910) es recull la hipòtesi de Capmany al voltant de l'existència d'un altre dietari a mans del nostre autor. Concretament, Capmany (1961-1963: v. II, p. 2;921) li atribueix el càrrec d'escrivà de l'ofici de Racional de l'Ajuntament de Barcelona. Malgrat aquesta referència, les Rúbriques de Bruniquer (1916: v. V, p. 294) no atribueixen cap càrrec a l'esmentat Vila, si bé això no descarta la possible existència d’un segon dietari. 


\section{E1 testimoni memorialístic}

Passem ara a tractar més exhaustivament el testimoni memorialístic de Jaume Ramon Vila que sí ens ha pervingut, el Dietari que conté notícies d'entre 1596 i 1601, centrades geogràficament en el Principat de Catalunya, tot i que amb la ciutat de Barcelona com a protagonista de la majoria dels capítols. L'obra ens ha arribat a través d'una única còpia, no autògrafa, que es conserva a l'AHCB, amb la signatura B-100. En les pàgines que conformen el Dietari trobem entrades adreçades a esdeveniments diversos, alguns amb un valor més institucional, i uns altres més vinculats als interessos o curiositats del seu autor: Vila hi recull visites reials, successos relacionats amb l'església i els seus membres, algun conflicte bèl lic de ressò al territori o la convocatòria de Corts el 1599, però també hi descriu els efectes de la mar sobre les muralles barcelonines, eclipsis solars o algun esdeveniment que quasi podríem denominar «miraculós». ${ }^{4}$

Advertim que Jaume Ramon Vila no va dur a terme un dietari pròpiament dit, malgrat que ell l'intitulà així. No ens trobem davant una obra en què s'escriu diàriament què ha esdevingut a la ciutat de Barcelona, sinó que l'autor construeix capítols temàtics que recullen tota la informació al voltant d'un assumpte concret; ben segurament, en un primer moment Vila confegí anotacions diàries que, en un pas posterior, s'haurien transformat en el dietari temàtic que coneixem en l'actualitat. Aquestes notícies conformaven capítols numerats, de manera que amb aquest sistema havia de resultar senzill recuperar informació d'un capítol en un altre, remetent a un sistema de numeració i, a més, evitava haver de repetir temes que ja havien estat tractats en altres moments del Dietari. És, per exemple, el mecanisme emprat per l'autor quan ens vol mostrar les celebracions que realitza la ciutat de Barcelona en arribar personalitats importants: Vila diu en una ocasió que «no pos assí lo modo que la present ciutat té en rébrer presidents perquè en lo capítol que tractaré de la entrada del duch de Feria per virrei o posaré llargament» (Dietari, p. 42).

Una mostra de com Vila aglutina les notes prèvies en una sola notícia és el capítol anomenat «Malaltia y mort del senyor rey don Phelip primer de Aragó y segon de Castella, fill del senyor emperador Carlos quint», en què l'autor recull tot allò relacionat amb la malaltia i mort de l'esmentat rei, que s'esdevé entre el 25 d'agost i el 20 d'octubre de 1598:

\footnotetext{
Dimars, a 25 de agost del present any 1598 [...] se sabé en la present ciutat per nova serta com la magestat del senyor rey don Phelip, primer de Aragó y segon de Castella [...] estava molt mal, ab gran perill de sa vida, en lo monestir de Sant Llorens. (Dietari, p. 169)

Dilluns, a 21 de setembre de dit any, reberen los diputats una carta de Miquel Ardèvol, [...] lo qual deya com diumenge, a 13 del matex mes de setembre, a la matinada, fou nostre Senyor servit de aportarse'n a la glòria la ànima del senyor rey don Phelip [...]. Dimars, a 22 de dit, se refermà molt la dita nova (Dietari, p. 169-170).

Divendres, a 9 de dit [i.e. octubre], se celebrà en la Seu lo aniversari per la ànima del senyor rey ab la solempnitat de la sepultura (Dietari, p. 182).
}

\footnotetext{
4 Podeu accedir a una descripció del manuscrit a MCEM (id. 934). També aportem un estudi detallat sobre un episodi bèl lic descrit al Dietari a Llàcer (2016b).
} 
Pel que fa a l'estructura en conjunt del Dietari, Vila pretenia recollir les notícies per anys, i agruparles en llibres - de manera que volia crear un «llibre» per a cadascun dels anys del Dietari. Com ja hem vist, aquest va passar per diferents «fases» de redacció, i en la transformació de les notes a capítols, a més, l'autor va dur a terme una valuosa tasca de combinació de l'escriptura original, fruit de l'experiència personal, amb tot un conjunt de fonts que utilitzava en la narració, bé com a complement del seu testimoni o, en alguna altra ocasió, com a font principal d'informació. ${ }^{5}$ Sols a través d'aquesta hipòtesi podem explicar que en diverses ocasions avance informació sobre esdeveniments que encara no han succeït, com hem vist en un exemple anterior, o que en altres casos indique que les dades que hi falten les aportarà en els capítols següents. A més, el mateix Vila ens parla, a la pàgina 97 del Dietari, d'uns «borradors» de l'obra: «aquest capítol tenia d'estar després del capítol terzer [...], però descuidím quant els borradors, lo copíy en lo present llibre; y també me descuidí de posar, en lo llibre primer de l’any 1596, la vinguda del cardenal de Guevara». ${ }^{6}$

Al llarg de tota l'obra trobem un seguit de referències a l'ordre dels capítols o als seus continguts que ens valdran per tractar de reconstruir l'obra així com va ser escrita per Jaume Ramon Vila, però abans de passar a analitzar el funcionament en el trasllat del Dietari amb què treballem, és imprescindible fer una breu descripció de les característiques que considerem que va tenir l'obra autògrafa i quines modificacions va sofrir el trasllat. D'entrada comptem amb què l'exemplar autògraf es composava de sis llibres - un llibre de notícies per a cadascun dels anys del Dietari-creats, com hem descrit, de la compilació d'unes notes prèvies que conformaven capítols temàtics numerats.

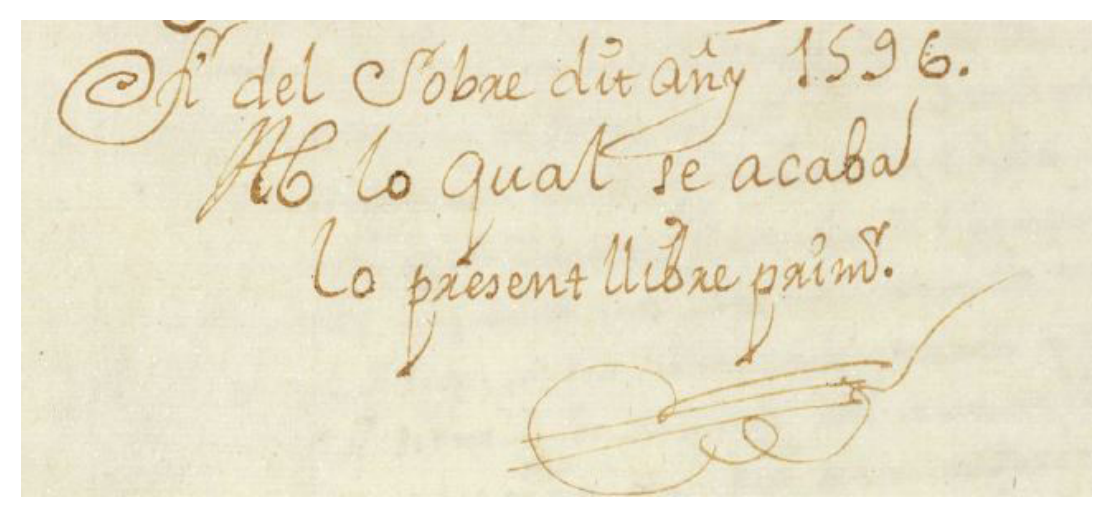

Indicació del final del llibre primer del Dietari al manuscrit B-100

A partir d'aquest exemplar es faria, com a mínim, una còpia parcial duta a terme per una sola mà, en què mancaven alguns dels capítols de l'obra autògrafa, uns altres haurien estar copiats de forma incompleta, i en la qual s'eliminava la numeració dels capítols, tot i que respectant les referències a

\footnotetext{
5 Sobre l'ús de les fonts ens remetem, novament, a Llàcer (2015) i Llàcer (2016b).

6 Advertim que la confecció d'un dietari mitjançant notes és habitual, com també el fet que sovint no trobem cap rastre del treball de construcció del relat (Amelang 2003: 114).
} 
la numeració de les notícies en el discurs. És a partir d'aquesta còpia duta a terme per una sola mà que es va realitzar el trasllat amb què treballem, el manuscrit B-100, que és una còpia a tres mans, una de les quals atribuïm a Joan Pau Colomer, bibliotecari dels Dalmases, d'on provindria aquest testimoni del Dietari de Jaume Ramon Vila. Com a conseqüència de ser el trasllat d'una còpia alterada, l'exemplar amb què treballem compta amb les mateixes modificacions, com a continuació veurem.

\section{El Dietari, una obra fragmentada?}

Com ja hem descrit en l'apartat anterior, malgrat que la idea inicial era, doncs, la de crear llibres anuals amb capítols temàtics numerats, l'exemplar de l'obra amb què treballem no segueix fidelment aquesta estructura, sinó que la numeració dels capítols sols apareix parcialment en els dos primers anys del Dietari. Amb tot, aquestes remissions han estat molt útils per identificar algunes de les notícies actualment perdudes o conèixer l'ordre d'unes altres que sí romanen dins el nostre exemplar però desordenades o sense numerar.

De l'anàlisi de les referències internes hem extret algunes dades que ens aproximen a conèixer una mica més l'obra així com va ser concebuda i escrita per Vila. D'entrada, la numeració dels capítols ha estat un element cabdal per a fonamentar les nostres sospites que treballem amb una còpia incompleta: mentre el manuscrit B-100 conté 81 capítols, les referències internes del text i la numeració dels dos primers anys del Dietari ens fan saber que sols amb els llibres de 1596 a 1599 l'obra comptava amb 75 capítols, als qual hem de sumar els 35 que com a mínim conformarien els llibres de 1600 i 1601, que ens donen com a resultat 110 capítols.

\begin{tabular}{|c|c|c|}
\hline ANY & MANUSCRIT B-100 & DIETARI AUTÒGRAF \\
\hline 1596 & 16 & mínim 26 \\
\hline 1597 & 5 & mínim 9 \\
\hline 1598 & 8 & mínim 18 \\
\hline 1599 & 17 & mínim 22 \\
\hline 1600 & 23 & mínim 23 \\
\hline 1601 & 12 & mínim 12 \\
\hline TOTAL & $\mathbf{8 1}$ & $\mathbf{1 1 0}$ \\
\hline
\end{tabular}

Graella de capitols que conformen el nostre exemplar i els capitols que, segons les referències, hauria tingut l'autògraf

Gràcies a aquestes petjades sobre l'estructura i continguts de l'autògraf sabem alguns dels capítols que es van copiar de forma incompleta o que van ser eliminats directament i també podem reconstruir, almenys parcialment, l'ordre d'algunes de les notícies del Dietari en l'autògraf. Veiem, en primer lloc, les notícies corresponents al primer «llibre», el de 1596; d'aquest primer any ha estat 
possible reordenar tres dels capítols, que en el trasllat han estat desplaçats. Pel que fa al capítol quart del nostre exemplar, que té per títol «Capítol de las informacions prengueren en Barcelona per la canonitsació de san Ramon de Penyafort y com obriren la sua sepultura y altres per dit afecte», hauria estat el sisè en l'autògraf, segons la informació següent: «en lo capitol 6 del present dietari se contenían llargament tots los procehiments que en la present ciutat se feren per la canonització de sant Ramon de Penyafort» (p. 351, notícies de 1600). ${ }^{7}$ De la mateixa manera, el capítol setè del trasllat, que té per títol «Capítol del [d]any que féu la mar a la muralla de San Fransech», hauria estat el quinze en l'autògraf, perquè segons indica el «Capítol de com la mar enderrocà la muralla de davant del monestir de Sant Francesch [...]», de les notícies de 1599, «en lo capitol 15 del primer llibre del present dietari està llargament contengut» (p. 266, notícies de 1599).

Igualment, el capítol que ocupa les primeres pàgines de les notícies d’aquest any -«Capítol de la vinguda de l'arcabisbe de Tarragona en la present ciutat y la canonitsació de san Ramon de Penyafort»- seria, a l'exemplar autògraf, el tercer: «després d'éser entrat lo arcabisbe de Tarragona en la present ciutat [...] conforme en lo capitol ters stà llargament contingut» (p. 6, notícies de 1596). Encara podem aportar un cas més, el d'una notícia traslladada parcialment; el capítol vint-i-tres, que conté el procés pel qual el duc de Feria va ser nomenat virrei, hauria de contenir, segons trobem a la pàgina 175 del Dietari, «protestacions ordinàrias, conforme està continuat en lo capítol 23 del primer llibre», una informació que no consta al capítol esmentat i que determina, per tant, que la còpia d'aquesta notícia és parcial.

Respecte del llibre corresponent a les notícies de 1597, l'estructura de l'exemplar amb què treballem respecta l'ordre dels tres primers capítols i passa del tercer al sisè, i d'aquest al capítol nou; ara estem en disposició d'aportar quines van ser algunes les modificacions del copista sobre l'ordre. En primer lloc, sabem que va eliminar el capítol quart, que hauria contingut algunes informacions sobre com els frares de Sant Francesc de Paula havien deixat el monestir. Vila indica que «en lo capitol quart del llibre segon del present dietari se ha vist com los frares de Sant Francisco de Paula havien dexat lo monestir» (p. 298, notícies de 1600). El segon cas que hi trobem està estretament vinculat al que just ara hem descrit, perquè el copista desplaça el capítol sisè, que tracta de la visita de dos cardenals a Barcelona, al quart lloc, i s'oblida de copiar l'original capítol quart del Dietari autògraf. El motiu d'aquest desplaçament ben segurament hauria estat provocat per les indicacions de Vila en el text: «aquest capítol tenia d'estar després del capitol terzer del present llibre que tracta de la obra de la Diputació per seguir lo orde del Dietari que ba per jornadas» (p. 79, notícies de 1597). Efectivament, confirmem que les obres de diputació són el tema del capítol tercer de les notícies de 1597, de manera que el copista, seguint les instruccions de l'autor, deixa sense copiar -no sabem si intencionadament- el capítol quart que tractava de l'eixida dels frares i situa en el seu lloc el capítol sisè.

Encara podem aportar algunes dades sobre com hauria estat confeccionat el Dietari de 1598. A hores d'ara sabem que aquest any de notícies hauria comptat amb un capítol tercer en què es

$7 \quad$ Utilitzarem la lletra cursiva per destacar la informació més important en cada cita d'aquest apartat. 
tractaria sobre un eclipsi solar, per la descripció que en fa Vila dels continguts: «lo [sic] qual [i.e. figura dibuixada de l'eclipsi] també tragué la altre que està posada en lo capitol tercer del llibre tercer del present Dietarì (p. 332, notícies de 1600). Respecte del primer capítol del manuscrit B-100, que tracta de l'arribada dels germans de Joan de Déu a Barcelona, seria el quart capítol del Dietari escrit per Vila per les indicacions i, igualment, el capítol en què es tracta del breu aconseguit pel bisbe Joan Dimas Lloris -que se situa en el capítol segon en la còpia- seria el cinquè en l'autògraf, com el mateix autor indica: «en lo capitol 5 del llibre tercer del primer volumen del present dietari se ha vist com lo molt reverent señor Don Juan Dimas Lloris, quòndam bisbe de Barcelona, alcançà breu de santedats (p. 363-364, notícies de 1601).

De la mateixa manera, el capítol sobre la mort del bisbe Joan Dimas Lloris ocuparia la posició onze en l'autògraf i no la quarta, ${ }^{8}$ segons indiquen les referències del text, i el capítol que tracta de la determinació del rei Felip III d'anar a casar-se a Barcelona seria el divuit en l'autògraf, i no el setè com trobem al trasllat; ${ }^{9}$ aquesta referència, a més, ens val per tal de saber el mínim de notícies que haurien composat el Dietari de 1598.

En aquest mateix llibre de notícies de 1598 es podria haver donat un fenomen del tot aillat en el Dietari, almenys per les informacions de què disposem fins ara. Jaume Ramon Vila va redactar un capítol de vint-i-quatre pàgines sobre la mort de Felip II i les exèquies que se celebraren a Barcelona. Fins ací no se'ns planteja cap dubte, però a l'inici del capítol següent trobem l'afirmació: «aprés de haver tractat en los 3 capítols precedents de la malaltia, mort y obsèquias del señor rey Phelip» (p. 193, notícies de 1598). Si ens fixem en l'índex dels capítols que conformen el Dietari de 1598 ràpidament comprovarem que aquests tres capítols no apareixen enlloc. Davant aquest buit d'informació se'ns plantegen dues possibilitats: d'una banda, i la més senzilla, és que el copista eliminara dos dels tres capítols al voltant d'aquesta temàtica; d'una altra, i aquesta és la hipòtesi més complexa, el copista podria haver unificat els tres capítols en un sol, tot i que advertim que revisantne el contingut no hem estat capaços de trobar les «costures» dels tres capítols originals. En cas que la hipòtesi correcta fora aquesta segona, seria un cas del tot extraordinari en el conjunt de l'obra, de manera que la primera opció que hem plantejat és la que ens sembla la més versemblant.

Respecte dels anys 1599, 1600 i 1601, hem pogut extraure molt poques dades al voltant de l'estructura original segons la va confeccionar l'autor del Dietari, perquè així com avancem en la lectura, la numeració dels capítols desapareix per complet i les referències a l'interior del text seran cada vegada menys nombroses. Malgrat aquest entrebanc, les «recuperacions» més remarcables que

8 Trobem la indicació sobre la posició que va ocupar aquest capítol a la pàgina 313 del Dietari: «per haver feta menció en lo capitol 11 del llibre tercer lo qual tracta de la malaltia, mort y obsèquies del que señor bisbe Lloris de la fundació del seminari de Montalegre».

9 Així s’indica a la pàgina 211 del Dietari: «En lo capitol 18 del llibre tercer del present dietari se ha vist clarament com seguida la mort del rey Phelip primer aprés de haver fetes y celebrades les sues obsèquies per lo señor rey Phelip segon, determinà de venir a casar en la present ciutat». 
hem estat capaços de detectar són les relacionades amb capítols que no podem trobar en el nostre exemplar però sí les petjades que els situen en l'exemplar autògraf de Jaume Ramon Vila. De fet, l'autor s'hi refereix en diverses ocasions a un episodi de pesta que va afectar Catalunya el 1599, amb comentaris com ara «per haver-i haguda molta pesta en alguns llochs de Cathalunya lo estiu passat de l'any 1599, quant lo señor rey se'n fou anat de la present ciutat» i especifica que aquesta no va afectar la ciutat comtal «vent la mercè que lo Señor nos ha feta en preservar esta ciutat de pestilència havent-n'i tanta en Cathalunya» (p. 330-331, notícies de 1600). Per tant, no ens sobtaria que hagués dedicat un capítol a aquesta temàtica, tot i que no el trobem ressenyat enlloc en el manuscrit B-100, ni tan sols mitjançant el número de capítol que hauria ocupat, com hem vist en altres ocasions fins ara.

En canvi, sí tenim la seguretat que va existir un capítol en les notícies de 1600 que narrava la mort d'uns capellans, perquè seguint els continguts del Dietari, se'ns diu que «y se'n tornà aprés a la professó a la seu per haver-i faltat de capellans en la Seu [...] com en lo capitol onse de aquest llibre 5 del present dietari està llargament dit» (p. 331, notícies de 1600). Igualment, el llibre de 1601 degué contenir un capítol al voltant de la canonització de Sant Ramon de Penyafort, i que no trobem al trasllat del Dietari que ens ha pervingut: «enviat que fou dit procés a Roma féu sa Santedat Clement octau las diligèncias que en tal se acostúman com en lo llibre següent veurem» (p. 351, notícies de 1600).

En aquest punt de l'anàlisi, encara ens hem d'ocupar d'alguns fragments més del Dietari, fragments que sobtadament es refereixen a esdeveniments que superen els límits temporals marcats per l'obra. Així, en el primer capítol de les notícies de 1596, aquell que rep per títol «Capítol I» en el trasllat i que hauria estat el primer del manuscrit autògraf, ${ }^{10}$ ens trobem la informació següent: «per estar las cosas de Franza y Inglaterra tant somogudes com sta vist en los capitols pasats» (p. 42), no cal dir que sent el primer capítol del primer llibre del Dietari, els «capitols pasats» als quals es refereix no són enlloc, i ni tan sols sabem si es refereixen a un esdeveniment datat del 1596 o d'anys anteriors, de qualsevol manera, l'existència d'uns capítols anteriors al «Capítol $\mathrm{l}$ » no encaixa en l'estructura del Dietari que fins ara coneixem.

De l'altre costat del límit temporal, el 1601, també ens trobem amb un parell de casos semblants: «captura dels diputats lo any vinent feren com en son lloch veurem» (p. 378, notícies de 1601); «restà dit negoci suspés que totom se pensava que no se'n parlaria més fins lo mes de mars de l'any vinent, per hont remet al lector a véurer proseguir esta tragèdia» (p. 400, notícies de 1601); «que los [i. e. els consellers] de l'any esdevenidor o feren molt bé ab las cosas de la Diputació, com veurem» (p. 420, notícies de 1601).

Els tres fragments es refereixen a esdeveniments que no formen part del trasllat amb què treballem $i$, tot $i$ que en el primer cas es pot referir a un fet ocorregut el 1601, els altres dos exemples que aportem es refereixen, sense cap mena de dubte, a notícies d'anys posteriors i que, com que el Dietari conté notícies fins el 1601, no formen part de l'obra així com la coneixem fins ara.

10 Considerem que aquest capítol és el primer de l'exemplar autògraf perquè així ho indica el títol: «Capítol I: de la entrada del duch de Maceda per virey de Catalunya» (p. 41-42, notícies de 1596). 
Per tant, en aquest punt de la recerca és innegable que ens hem de formular la qüestió de si el Dietari es limita als anys que al llarg d'aquestes pàgines hem enunciat reiteradament, són els límits temporals el 1596 i el 1601? Tot i que no tenim una resposta ferma sobre la referència a esdeveniments anteriors al 1596, sí podem posar una mica de llum sobre on haurien estat narrades les notícies posteriors al 1601: en una segona part del Dietari que, actualment, donem per perduda, i ho pensem així perquè és l'autor qui es refereix a una estructura de l'obra en més d'un volum:

En lo capítol 5 del llibre tercer del primer volumen del present dietari se ha vist com lo molt reverent señor Don Juan Dimas Lloris [...] alcançà breu de santedat per aque ell a solas y sens adjunt pogués ell y sos successors visitar la Seu, Capítol y tot lo demés (p. 363-364, notícies de 1601

\section{Conclusions}

Una vegada estudiats tots els casos sobre l'alteració de l'ordre dels continguts i l'eliminació de capítols dins l'obra dietarística de Vila que hem detectat, i que fins ara no havien estat descrits, podem extraure algunes conclusions. En primer lloc, determinem que el manuscrit B-100, que és fins ara l'únic testimoni que es conserva del Dietari de Jaume Ramon Vila, és, sens dubte, una còpia incompleta. Així, seguint les dades que hem aportat en aquest estudi, ens ha pervingut, com a màxim, el $70 \%$ del contingut de l'obra, tot i que som del pensament que, dissortadament, el percentatge real no arribarà al 50\% de l'edició autògrafa.

En segon lloc, podem ratificar que la intervenció del copista primer -autor del trasllat a partir del qual s'elabora la còpia amb què treballem- és evident, si bé és cert que no hem estat capaços de trobar un patró concret pel que fa a la selecció dels continguts que decideix copiar. Altrament, sí podem justificar, encara que siga parcialment, la reordenació dels capítols duta a terme per aquesta mà. Fixant-nos en les dates de les notícies corresponents a 1596, comprovem que el copista duu a terme aquesta tasca de reordenació per tal de corregir alguns desordres cronològics que atribuïm a Jaume Ramon Vila. Per exemple, si haguera mantingut el «capítol I» en la primera posició en la còpia, les notícies haurien començat en el mes d'agost i després haurien retrocedit a esdeveniments de mesos anteriors, mentre que en el trasllat la primera entrada correspon a un esdeveniment del mes de març i la resta dels capítols segueixen un ordre temporal lineal, sense salts. D'aquesta manera, els diferents desplaçaments de contingut a mans del copista responen a una correcció de caire cronològic atés que, en general, Jaume Ramon Vila duu a terme un Dietari que segueix una línia temporal ordenada, que en poques ocasions es veu alterada i, en cas de ser així, l'autor ho indica i n'explica els motius.

En tercer lloc, cal tenir en compte que dissortadament sols comptem amb un trasllat parcial d'aquesta obra dietarística a mans de mossèn Vila, i aquest fet dificulta la tasca de recuperació de continguts, més enllà de les subtils línies que en aquest article hem estat capaços de dibuixar. Sols en el cas que s'haguera conservat un segon trasllat del Dietari que no fora descendent del mateix copista primer 
a partir del qual es va elaborar l'únic exemplar de l'obra que coneixem fins ara, podríem tractar de reconstruir les peces perdudes del trencaclosques que és, a hores d'ara, aquest testimoni dietarístic.

Finalment, i seguint la idea descrita just dalt, hem de destacar que el Dietari, almenys així com el va concebre Jaume Ramon Vila, hauria estat conformat per dos volums, un que correspondria a les notícies del Principat de Catalunya entre 1596 i 1601 aproximadament i, un segon volum amb notícies a partir del 1602, del qual sols sabem que l'autor pretenia dur a terme, perquè la realitat és que no s'ha conservat cap rastre de la seua existència més enllà del fragment que en aquest estudi hem aportat. Ens plantegem el dubte de si els dos volums del Dietari es van conservar en llocs diferents, perquè de ser així, el segon volum podria ajustar-se a la descripció del «dietari de Ramon Vila» que apuntàvem a l'inici de l'article, en parlar del manuscrit A-1; a hores d'ara, però, sols estem en disposició d'apuntar aquesta possibilitat com una hipòtesi que requereix d'un estudi aprofundit.

\section{Bibliografia}

AHCB, ms. A-1, Rafael Cervera, Recull de dietaris i notícies dels anys 1249-1628.

AHCB, ms. B-100, Jaume Ramon Vila, Dietari (1596-1601).

Amelang, James (2003) El vuelo de Icaro: la autobiografía popular en la Europa moderna. Madrid. Siglo XxI de España.

Aymar, Jaime (1999) «La biblioteca del Monasterio de Sant Jeroni de la Murtra» dins La Orden de San Jerónimo y sus Monasterios, Actas del II Simposium. Madrid. Ediciones Escurialenses (p. 691-710).

Batlle, Mar (1999) Patriotisme i modernitat a La fi del comte d'Urgell. Una aproximació a les fonts de l'obra. L'anònim autor i historiador Jaume Ramon Vila. Barcelona. Curial Edicions Catalanes-Publicacions de l'Abadia de Montserrat.

BC, ms. 505, Rafael Cervera, Miscel lània històrica.

Bruniquer, Esteve Gilabert de (1916) Ceremonial dels magnifichs consellers y regiment de la ciutat de Barcelona, Barcelona. Henrich, v. v.

Capmany, Antoni de (1961-1963) Memórias históricas sobre la marina, comercio y artes de la Antigua Ciudad de Barcelona, Barcelona. Cámara Oficial de Comercio y Navegación; v. II. [1a ed. 1779-1792].

Duran, Eulàlia (1982) «Unes cartes amoroses del segle Xvi en català», L'Espill, 15 (p. 25-51).

Llàcer, Arantxa (2015) «Aproximació a les fonts del Dietari de Jaume Ramon Vila (AHCB, ms. b-100)», Mirabilia / MedTrans 1 (p. 159-175). Disponible en línia a http://www.revistamirabilia. com/sites/default/files/medtrans/pdfs/01-07.pdf ]

(2016a) «Jaume Ramon Vila i la seua relació amb Sant Jeroni de la Murtra a través dels manuscrits del Monestir», Revista Carrer dels arbres [en premsa]. 
(2016b) «Traducir noticias en el siglo XVII. Notas sobre fuentes y lenguas de escritura memorialística», Mirabilia / MedTrans [en premsa].

Roca, Josep (1918) «En Jaume Ramon Vila, heraldista català de començaments del s. XVII» dins Discursos llegits en la "Real Academia de las Buenas Letras" de Barcelona en la solemne recepció pública de Don Joseph Roca. Barcelona. Impremta de la Casa Provincial de Caritat.

Roca, Josep (1928) «Més dades biogràfiques d'en Jaume Ramon Vila» dins Butlletí de la Reial Acadèmia de Bones Lletres de Barcelona, v. 13 (p. 163-178). Disponible en línia a [http://raco.cat/index.php/ BoletinRABL/article/view/199961/275790] 